\title{
Mathematical Modelling of Thermal Stratification and Drainage of Steel Ladles
}

\author{
P. R. AUSTIN, J. M. CAMPLIN, J. HERBERTSON and I. J. TAGgART ${ }^{1)}$
}

BHP Research Newcastle Laboratories, PO Box 188, Wallsend, NSW 2287, Australia. Engineering, University of New South Wales, Anzac Pde, Kensington, NSW 2033, Australia.

1) Department of Petroleum

(Received on August 23, 1991; accepted in final form on November 15, 1991)

\begin{abstract}
Transient analysis of the temperature and velocity distributions of steel during ladle standing and draining has been conducted using a mathematical model based on the PHOENICS numerical package. Parameters investigated were stand time, average steel cooling rate, drainage rate and ladle geometry. Stratification was seen to develop due to natural convection, and the rate of stratification was found to be linearly dependent on the average steel cooling rate, independent of ladle geometry. Qualitative relationships were found between the parameters and the teeming temperature during draining. Plant trials showed good agreement between simulated and actual teeming temperatures.
\end{abstract}

KEY WORDS: thermal stratification; mathematical model; natural convection; drainage; ladle.

\section{Introduction}

The temperature of liquid steel supplied to a continuous caster via a tundish must be controlled to tight limits. Too high casting temperatures can result in poor quality steel due to excessive levels of centreline segregation in the solidified product. At low temperatures, approaching the liquidus, problems of nozzle blockage, tundish freeze-ups and excessive ladle skull formation are accentuated.

The most important factor governing the bulk tundish temperature during casting is the temperature of steel emerging from the ladle. The average steel temperature in the ladle can be quantified with reasonable accuracy by taking into account the sources and mechanisms of heat loss. ${ }^{1,2)}$ However, the temperature variations of steel in the ladle, referred to as temperature stratification, must also be considered as this can have a marked influence on the ladle stream temperature. Ideally, the stream temperature should not exhibit a strong time dependent behaviour as this may result in large temperature variations in the tundish during ladle draining.

Hlinka and Miller ${ }^{3)}$ have shown that variations in ladle pouring temperatures occur due to heat losses from the molten steel into the surrounding refractory layers. This is a transient process and gives rise to turbulent natural convection currents within the molten steel. Ilegbusi and Szekely ${ }^{4)}$ have simulated this process and the subsequent development of stratified layers. Stratification results in the placement of colder, more dense layers of fluid beneath warmer, less dense ones. The calculations of Ilegbusi and Szekely focussed on reducing the influence of stratification through the use of magnetic stirring to promote bulk mixing. However, their work stopped at the teeming stage, which represents an important and achievable next step towards actual plant situations.

The purpose of this work is to examine the impact which stratification has on subsequent 'pouring temperatures. This is accomplished by extending our numerical analysis of the evolution of natural convection and thermal stratification. The effect on the ladle stream temperature of various ladle cooling rates, stand times and drainage rates is calculated. In addition, the influence of ladle size is considered, as simulations are performed for 125, 200 and 275 tonne ladles. These capacities correspond respectively to the ladles used at BHP Steel production plants, namely Long Product Division in Whyalla (LPD), Rod and Bar Products Division in Newcastle (RBPD) and Slab and Plate Products Division in Port Kembla (SPPD). The theoretical predictions are compared to actual ladle stream temperatures.

\section{Formulation}

The ladle is modelled as a cylinder of radius $R$ containing steel to a depth $H$. The effect of wall inclination is assumed to be negligible. The simulation begins with an assumed homogeneous and quiescent ladle full of molten steel. Heat is transferred from the steel to the bounding refractory surfaces. The top surface is assumed well insulated. Due to the heat losses, fluid elements close to the wall become cooler and therefore more dense. Under the influence of gravity, these fluid elements sink, giving rise to natural convection currents. In the absence of drainage, these convection currents are responsible for forming colder layers of 
fluid at the bottom of the ladle. When drainage commences, it is these cooler layers which flow out first.

The problem is to calculate the velocity and thermal fields which result during the ladle stand and drainage cycles, and to examine how these results vary with different operating strategies. The problem may be readily stated in the form of differential mass, momentum and energy balances, which take the following form:

$$
\begin{aligned}
& \text { Mass } \nabla \cdot \rho \tilde{u}=0 \\
& \text { Momentum } \frac{\partial(\rho \tilde{u})}{\partial t}+\tilde{u} \cdot \nabla(\rho \tilde{u}) \\
& =-\nabla P+\nabla \cdot\left(\left(\mu_{l}+\mu_{t}\right) \nabla \tilde{u}\right)+\widetilde{F}_{B} \\
& \text {........................(2) } \\
& \text { Energy } \frac{\partial(\rho h)}{\partial t}+\tilde{u} \cdot \nabla(\rho h)=\nabla \cdot\left(\left(\frac{\kappa}{c_{p}}+\frac{\mu_{t}}{\sigma_{h}}\right) \nabla h\right)
\end{aligned}
$$

In the above equations, $\mu_{t}$ is the turbulent viscosity calculated through the use of the standard $k-\varepsilon$ turbulence model. ${ }^{5}$ Briefly, the turbulence model is an approximation which takes account of the fact that the diffusive transport of momentum and energy is enhanced in a turbulent flow. Away from solid walls, turbulent diffusion of heat and momentum dominates laminar diffusion.

$\tilde{F}_{B}$ represents the buoyancy force, given by

$$
\tilde{F}_{B}=\rho \tilde{g}\left(1-\beta\left(T-T_{r e f}\right)\right)
$$

This states that as a fluid element decreases in temperature it experiences a greater force in the direction of $\tilde{g}$. The buoyancy term is responsible for the coupling of the momentum and energy equations.

Velocity boundary conditions used were zero shear at the free surface during stand time, and no-slip conditions along the walls. Frictional losses near the walls were modelled using wall functions. ${ }^{5}$ Turbulence boundary conditions for $k-\varepsilon$ were obtained using wall functions for those elements adjacent to refractories in the standard manner. ${ }^{5)}$

During draining, the top free surface was replaced by a uniform inflow surface having zero normal gradient of enthalpy. In this manner the downward motion of the free surface was not explicitly simulated; instead material was added to the upper surface at a rate equal to the outflow. The inflowing material is allowed to mix with the fluid already in the ladle. This did not introduce any significant error into the results. Test simulations using a time-varying grid to model the free surface gave very similar pouring stream temperature predictions, and were computationally more intensive. The simpler fixed grid model was thus used.

Symmetry was exploited where possible in the numerical grid. The mean ladle radius was used to produce an axisymmetric cylindrical grid of $15 \times 20(r, z)$ cells for the ladle standing calculations. For the ladle drainage calculations, the taphole was located on the bottom surface at $2 / 3$ radius, necessitating the use of a three dimensional flow simulation. A hemi-cylindrical $15 \times 10 \times 20(r, \phi, z)$ grid was used.

Enthalpy was normalized to overcome roundoff problems. The initial temperature of the steel was taken as the reference zero temperature, and subsequently only enthalpy differences from that zero were calculated. This report thus presents temperatures as deviations from the reference zero.

Enthalpy boundary conditions were zero gradient at the upper surface, and uniform heat flux over the ladle walls and base. These conditions are quite simplistic, but in the absence of a full ladle heat transfer model, seem reasonable assumptions. The flux was adjusted iteratively for the ladle standing cases, but fixed for the drainage cases. At each full field iteration during a standing simulation, the bulk cooling rate was found by averaging temperature over the ladle volume. The heat flux was then adjusted to bring the rate into agreement with the prescribed bulk cooling rate.

Equations (1) to (3) were solved using the flow simulation package PHOENICS version 1.5. Run times on a VAX 8650 were of the order of 30 and $150 \mathrm{~min}$ for the standing and draining calculations respectively.

\section{Simulated Cases}

Table 1 shows the configuration of the ladles that were simulated together with the values of the thermophysical properties of steel used in the calculations. The process variables investigated were the ladle cooling rate, stand time and drainage rate. The ladle cooling rate was specified as the average cooling rate of the steel through the refractories. At RBPD, for example, plant experience has shown that steel in a well cycled ladle will lose temperature at $0.25^{\circ} \mathrm{C} / \mathrm{min}$ and for a new ladle $0.5^{\circ} \mathrm{C} / \mathrm{min}$. The stand time was defined as the

\begin{tabular}{|c|c|c|c|}
\hline \multicolumn{2}{|l|}{ Parameter } & Value & Units \\
\hline \multicolumn{2}{|l|}{ Density $(\rho)$} & 7000 & $\mathrm{~kg} / \mathrm{m}^{3}$ \\
\hline \multicolumn{2}{|c|}{ Thermal expansion coeff. $(\beta)$} & 0.0002 & $1 /{ }^{\circ} \mathrm{C}$ \\
\hline \multicolumn{2}{|c|}{ Viscosity $(\mu)$} & 0.001 & $\mathrm{~Pa} \cdot \mathrm{s}$ \\
\hline \multicolumn{2}{|c|}{ Specific heat $\left(C_{p}\right)$} & 627 & $\mathrm{~J} / \mathrm{kg} \cdot{ }^{\circ} \mathrm{C}$ \\
\hline \multicolumn{2}{|c|}{ Prandtl No. $\left(\sigma_{h}\right)$} & 0.9 & - \\
\hline \multirow[t]{3}{*}{ Radius $(r)$} & SPPD & 1.789 & $\mathrm{~m}$ \\
\hline & RBPD & 1.65 & $\mathrm{~m}$ \\
\hline & LPD & 1.316 & $\mathrm{~m}$ \\
\hline \multirow[t]{3}{*}{ Height $(h)$} & SPPD & 4.242 & $\mathrm{~m}$ \\
\hline & RBPD & 3.45 & $\mathrm{~m}$ \\
\hline & LPD & 2.92 & $\mathrm{~m}$ \\
\hline
\end{tabular}
period between the end of ladle treatment to the start of ladle teeming. The range of operational conditions simulated for each individual plant are summarised in Table 2.

Table 1. Parameters used in calculations.

Table 2. Range of process variables simulated.

\begin{tabular}{lcccc} 
& & \multicolumn{3}{c}{ Ladle size } \\
Process variables & $\begin{array}{c}275 \mathrm{t} \\
\text { SPPD }\end{array}$ & $\begin{array}{c}200 \mathrm{t} \\
\text { RBPD }\end{array}$ & $\begin{array}{c}125 \mathrm{t} \\
\text { LPD }\end{array}$ \\
& & & & \\
& & & & \\
\hline $\begin{array}{l}\text { Cooling rate } \\
\text { into refractories }\end{array}$ & $\left({ }^{\circ} \mathrm{C} / \mathrm{min}\right)$ & $0.125-0.50$ & $0.125-0.50$ & $0.6-1.0$ \\
$\begin{array}{l}\text { Ladle stand time } \\
\text { Ladle drainage rate }(\mathrm{m} / \mathrm{h})\end{array}$ & $15-45$ & $15-45$ & $13-25$ \\
\hline
\end{tabular}




\section{Stratification Results}

Figure 1 shows the predicted velocity vector and isotherm fields for a 200 tonne ladle which has experienced a cooling rate of $0.5^{\circ} \mathrm{C} / \mathrm{min}$ for $15 \mathrm{~min}$. The isotherms are flat, except for a strong local wall effect generated by the cooling from the adjacent refractories. Near the walls colder, more dense, fluid sinks under the influence of gravity producing one dominant toroidal recirculation pattern. The result of this motion is to place the colder fluid on the bottom of the ladle. This is a final stable configuration and consequently greater vertical

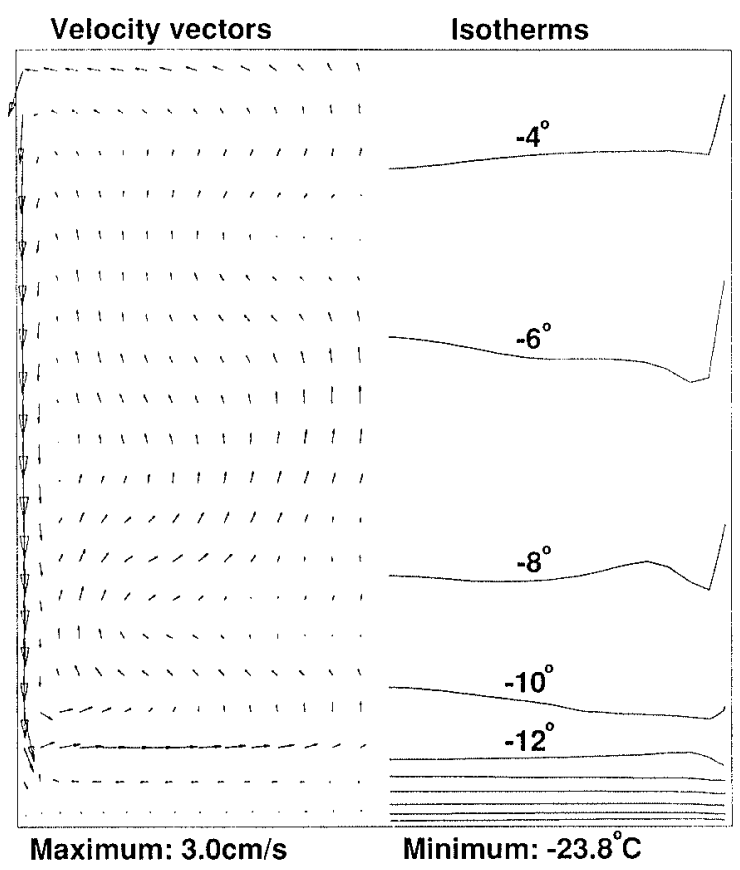

Fig. 1. Velocity vectors and isotherm fields after $15 \mathrm{~min}$ stand time for a 200 tonne ladle. Cooling rate $=$ $0.5^{\circ} \mathrm{C} / \mathrm{min}$.

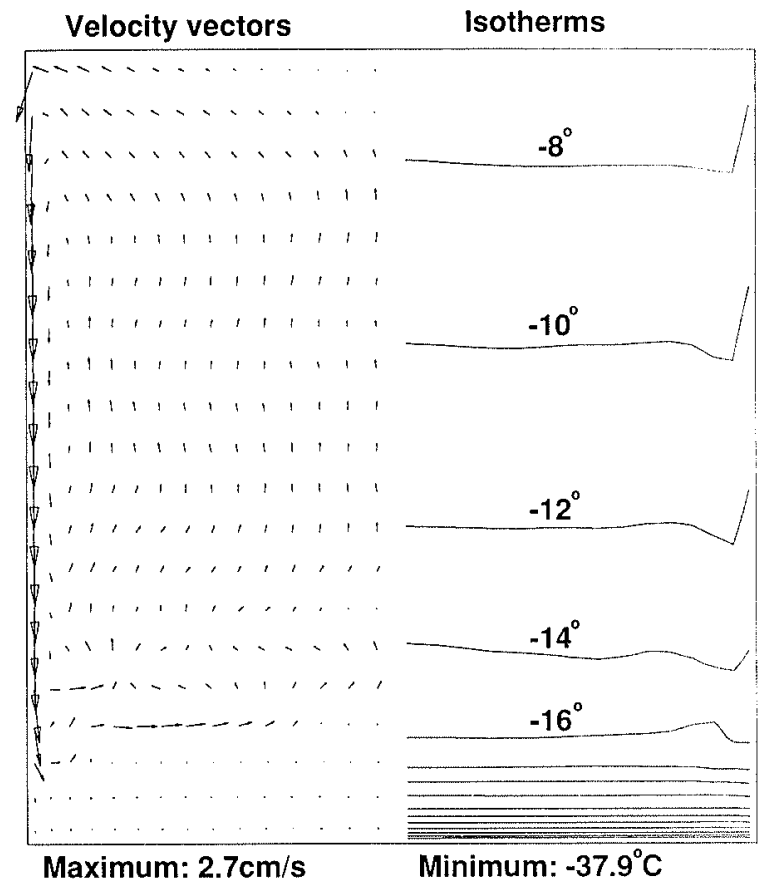

Fig. 2. As Fig. 1, after 25 min stand time. thermal gradients are created in this region. The predicted fields are in close agreement with Ilegbusi and Szekely ${ }^{4)}$ for a large volume ladle.

Figures $\mathbf{2}$ and $\mathbf{3}$ depict the velocity vector and isotherm fields for the same ladle after standing times of 25 and $45 \mathrm{~min}$ respectively. The isotherms illustrate that stratification is seen to be increasing with standing time. It is noticeable that the magnitude of the velocity vectors decrease and also the size of the recirculation region diminishes. Indeed, as shown in Fig. 4 , the maximum values of the velocities after 1,15 and $45 \mathrm{~min}$ were $7.5,3.0$ and $2.5 \mathrm{~cm} / \mathrm{s}$, which reflects the fact that the driving force for convection is strongest at the start.

Figure $\mathbf{5}$ shows temperature history for centreline top and bottom positions. The difference between these two lines is the temperature stratification, $\tau$.

Figure 6 shows this difference $\tau$, plotted against time, for different bulk cooling rates, $\dot{c}$. After an initial period, the rate of development of stratification, $\dot{\tau}$, is near linear. This occurred with all ladle geometries studied.

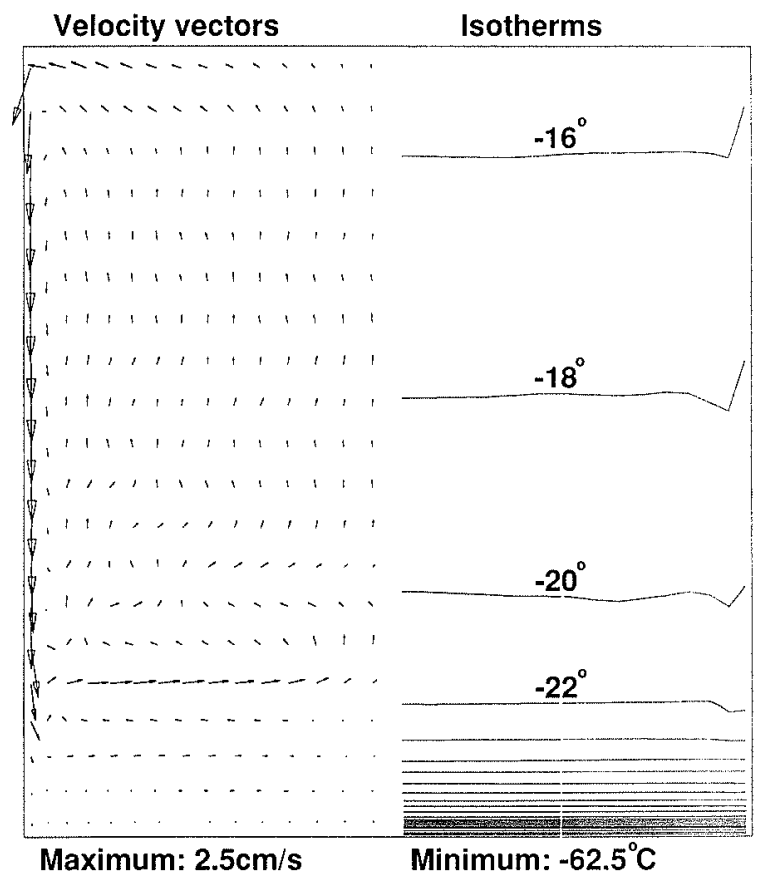

Fig. 3. As Fig. 1, after $45 \mathrm{~min}$ stand time.

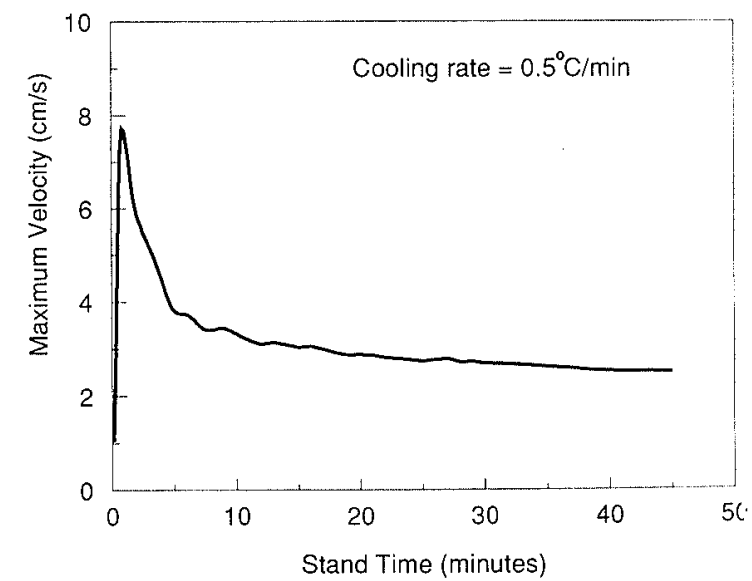

Fig. 4. Maximum velocity as a function of time for a 200 tonne ladle. 
The near linearity of the curves in Fig. 6, indicates that there is a relatively simple relationship between $\dot{\tau}$ and $\dot{c}$. In Fig. 7 these variables are plotted using data for the SPPD, RBPD and LPD ladles.

From the slope of the plots it can be shown that the rate of development of stratification, $\dot{\tau}$ can be represented empirically by

$$
\dot{\tau}=2.0 \dot{c}
$$

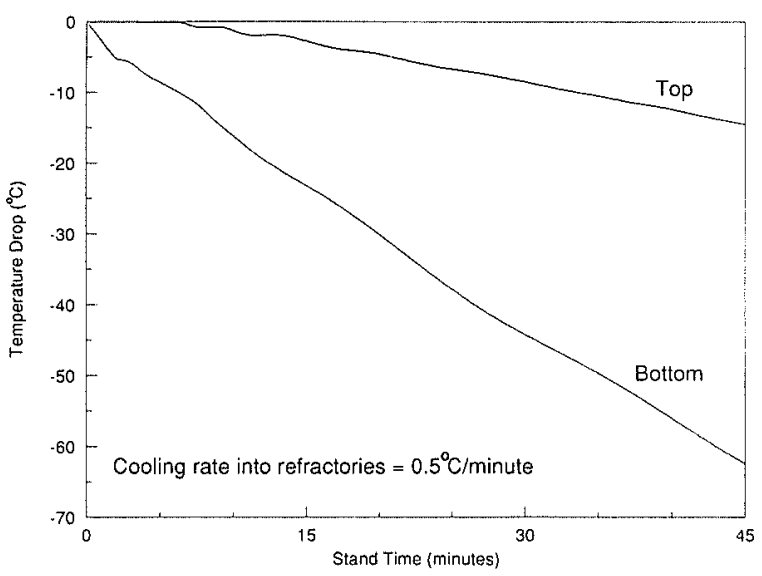

Fig. 5. Stratification development with time for ladle centreline top and bottom temperatures.

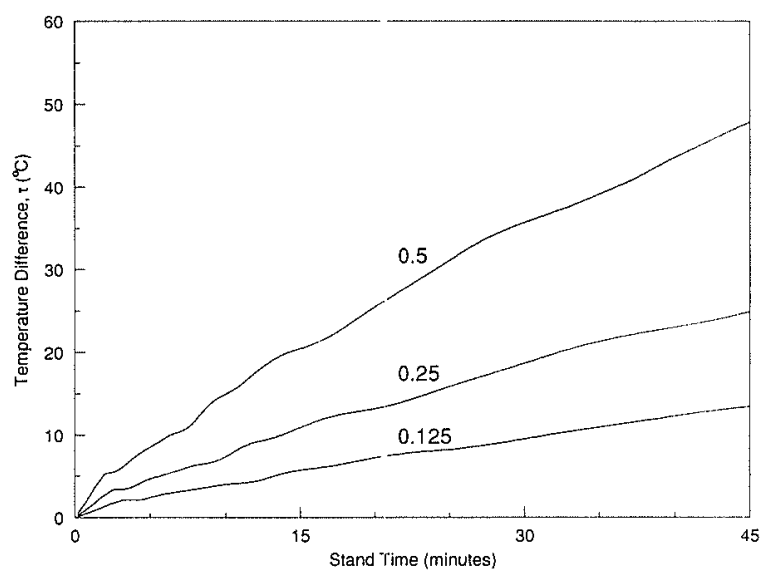

Fig. 6. Stratification development, taken as the difference between centreline top and bottom temperatures, with time, for different cooling rates. Curve notation is $\dot{c}$ $\left({ }^{\circ} \mathrm{C} / \mathrm{min}\right)$.

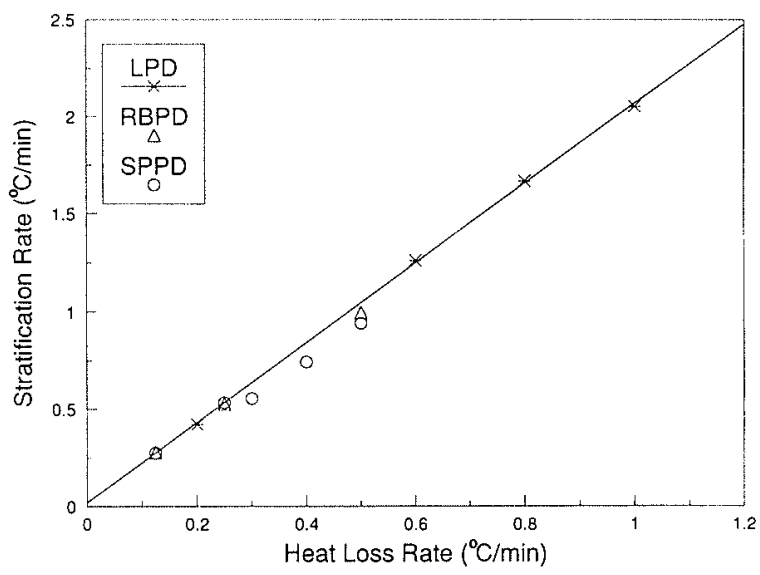

Fig. 7. Stratification rate as a function of heat loss rate for various ladle geometries.
Thus, it is seen that cooling rate and the stratification rate are directly proportional, giving a characteristic dimensionless number for all BHP ladles of 2.0, this being the gradient of the line of best fit. Equation (5) therefore gives a practical measure of stratification according to ladle heat losses and holding time. For example, using this relationship it can be estimated that there will be a temperature difference between the top and bottom of $20^{\circ} \mathrm{C}$, for a ladle held for $40 \mathrm{~min}$ with an average cooling rate of $0.25^{\circ} \mathrm{C} / \mathrm{min}$. A delay of 10 min in opening will result in an additional $5^{\circ} \mathrm{C}$ of stratification.

\section{Drainage Results}

As fluid flows out of the nozzle from a stratified ladle its temperature at the exit point reflects the liquid withdrawal pattern within the ladle. The effect of drainage on the bulk flow pattern is expected to be quite significant. On this basis we can anticipate that high and low drainage rates will influence the uniformity of the steel exiting the ladle.

Figure 8 shows the pouring stream temperature, for the first eighty tonnes, of an SPPD ladle which has experienced an average cooling rate of $0.25^{\circ} \mathrm{C} / \mathrm{min}$. Drainage rates of 250,750 and 1500 tonnes/h have been considered. Curve notation is "stand time (min)/ drainage rate (tonnes/h)". As expected, the figure shows that longer stand times give lower initial temperatures. In addition, the results indicate that for minimal stand times (less than $15 \mathrm{~min}$ ) the ladle exit stream temperature is largely independent of casting time due to the lesser amount of stratification which can occur during a brief stand time. This may be compared to a stand time of $45 \mathrm{~min}$ or greater for which the first few tonnes may be at least some $5^{\circ} \mathrm{C}$ cooler than the stream temperature at the forty tonne mark.

The behaviour is more pronounced in the case of a ladle undergoing an average cooling rate of $0.5^{\circ} \mathrm{C} / \mathrm{min}$, as shown in Fig. 9. Considering stand times of $45 \mathrm{~min}$, at drainage rates of 750 and 1500 tonnes $/ \mathrm{h}$, the temperature increases markedly over the first 60 tonnes. In the case of the lower teeming rate, 250 tonnes $/ \mathrm{h}$, the

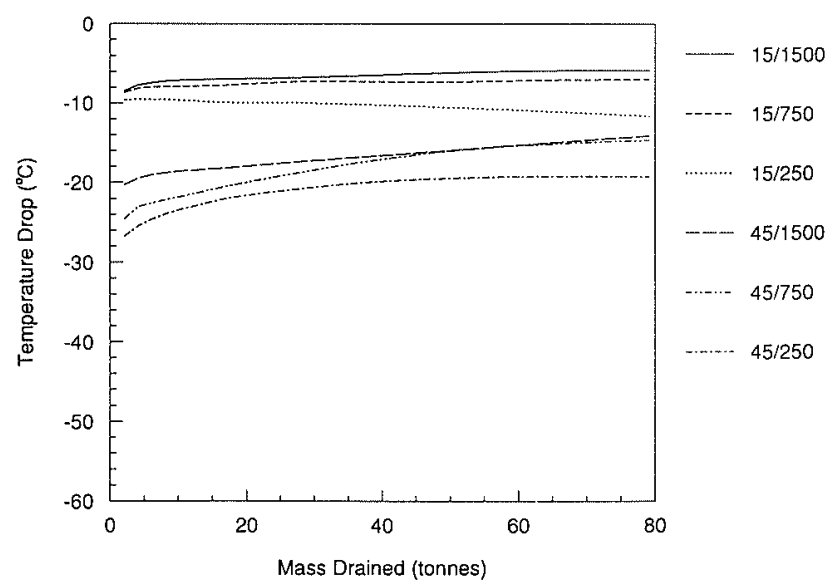

Fig. 8. Change in pouring stream temperature with drainage Cooling rate $=0.25^{\circ} \mathrm{C} / \mathrm{min}$. Curve notation is stand time $(\mathrm{min}) /$ drainage rate $($ tonne $/ \mathrm{h}$ ). 


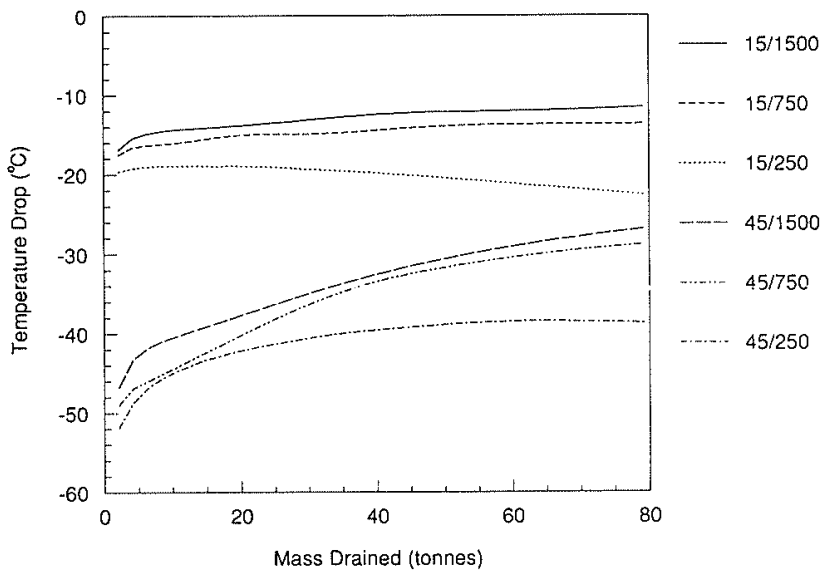

Fig. 9. As Fig. 8, with cooling rate $=0.5^{\circ} \mathrm{C} / \mathrm{min}$.
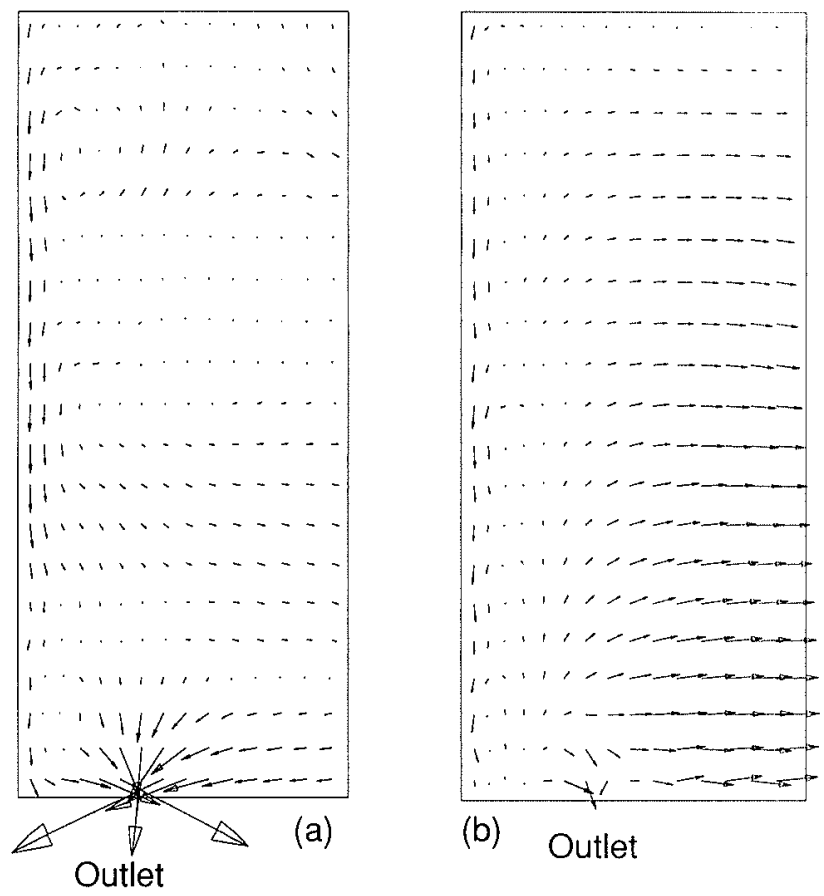

(b) Outlet

Fig. 10. Velocity vector fields, in the vertical plane containing the outlet, for an SPPD ladle, 45 min stand time, with drainage rates of (a) 1500 and (b) 250 tonnes $/ \mathrm{h}$ respectively. Note that the outflow dominates the velocity field in the first case, but influences the second case by creating large horizontal recirculations. Only half the ladle is shown in each figure.

temperature increase is much less. This indicates that in a stratified ladle, high drainage rates will encourage fluid flow toward the nozzle from the relatively warmer upper regions of the ladle, as the drainage currents dominate the recirculatory natural convection currents. This is supported by Fig. 10, which contrasts velocity vector fields predicted for drainage rates of 1500 and 250 tonnes/h. For the high drainage rate case, the outflow dominates the flow pattern, and liquid is drawn towards the outlet from all regions within the ladle. For the low drainage case, the small off-centre outflow promotes the formation of large vortices, and outflow is sourced mainly from the bottom of the ladle.

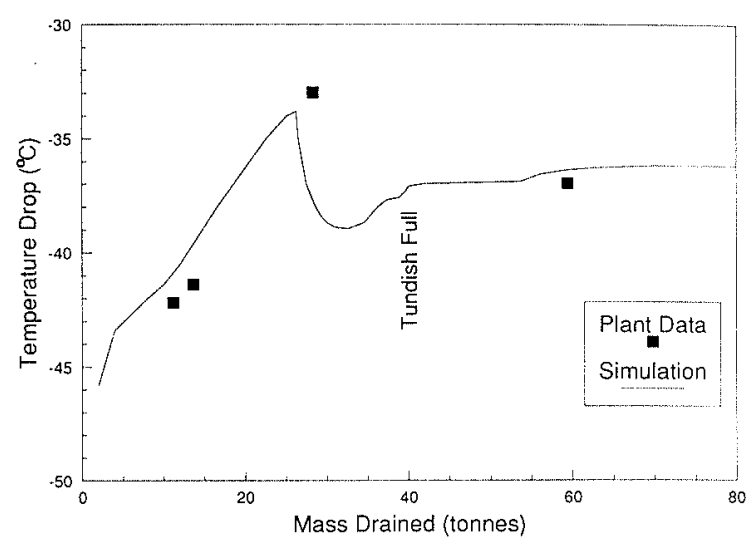

Fig. 11. Comparison of plant data for first heat $\left(0.5^{\circ} \mathrm{C} / \mathrm{min}\right.$ cooling) into a new tundish with simulated results.

\section{Comparison with Plant Data}

Figure 11 shows the comparison between a numerical simulation and an actual plant trial where pouring stream temperatures from a 200 tonne ladle were measured during the filling of a new tundish at RBPD. Due to casting requirements the pouring rate into an empty or near empty tundish is not uniform but instead proceeds from an initial high rate down to a level dictated by the casting speed.

The condition of the ladle was such that a cooling rate of $0.5^{\circ} \mathrm{C} / \mathrm{min}$ could be expected. Its stand time, that is the time from end of bubbling at ladle treatment to ladle opening, was approximately $45 \mathrm{~min}$. For the first 28 tonnes the drainage rate was 750 tonnes $/$ h. The rate was then decreased to 150 tonnes/h for the next 10 tonnes and then 300 tonnes/h thereafter.

The agreement between the simulated and actual temperatures is very good and also explains why a peak temperature appears around the 28 tonne mark. This peak exists because at the higher drainage rates considerably warmer material begins to appear at the taphole at this time. When the flow rate is suddenly cut back, the material which flows out, comes primarily from the cooler regions adjacent to the nozzle. Here a local peak in temperature is recorded whose peak size is approximately 5 to 6 degrees.

\section{Discussion}

Since the fluid flow is driven by heat losses the rate of development of stratification is dependent on the thermal state of the ladle. The simulations have highlighted this point and allowed a quantitative estimate of the rate of development of stratification based on the average temperature loss of the steel into the refractories.

Analysis of the results revealed that the rate of stratification, $\dot{\tau}$, proceeds at twice the average temperature loss into the refractories, $\dot{\tau}$. This phenomena was seen to be independent of ladle size as the relationship $\dot{\tau}=2.0 \dot{c}$ held for 125,200 and 275 tonne ladles. This finding is consistent with the experience of Ilegbusi and Szekely $^{4)}$ who reported that the stratification behaviour was similar for $7.5,80$ and 200 tonne ladles. 
The seriousness or otherwise of this stratification is related to the tundish filling strategy. Filling the tundish at a faster rate initially leads to hotter fluid layers being drained. Based on this result it can be conjectured that larger tundish systems, as they allow a greater scope for higher initial drainage rates, would be less prone to temperature variations than smaller systems.

The liquid recirculation pattern is dominated by the wall flow, with near plug vertical flow over the majority of the ladle. Note from Fig. 1 that the wall flow is almost entirely restricted to the outermost column of computational cells. This would seem to imply that the boundary layer thickness is grid dependent. However, as the computational mesh was made finer, the pattern of stratification within the ladle did not vary significantly, even though the thickness of the descending fluid layer did decrease slightly. The mesh density used in the calculations was thus chosen so as to represent this boundary layer satisfactorily, yet not demand exorbitant computational times.

The velocity vectors plotted in Figs. 1, 2 and 3 appear to contain irregularities near the lower section of the wall and along the central axis. These are not due to circumferential motion, as the solutions are 2 dimensional. At first they were thought to be due to unconverged numerical solutions. However, after refining the convergence tolerance, the vortex-like features persisted. Grid dependence was investigated by doubling the spatial grid and halving the time step used, but this did not alter the solution significantly. Further, the velocity vector irregularities were not eliminated when the $k-\varepsilon$ turbulence model was replaced with the Prandtl energy model, which uses $k$ and a length scale. Thus these unsteady fluctuations appear as an actual part of the solution of the equations.

The source of such velocity fluctuations could be one of several possibilities. Most probably, they arise from the initial conditions of a quiescent homogeneous ladle, coupled with the transient nature of the problem. The large natural convection flow near the wall creates a temporarily large axial jet-like upward flow. The form of this central flow initially oscillates between a strong axial jet and a weaker mid-radial toroidal jet. As the solution progresses, the strength of these two extremes decays, resulting in a low-speed plug flow field over the inner two thirds of the radius of the ladle. When this process is viewed by computer animation, it is apparent that in the early stages of the solution, large toroidal vortices form near the ladle surface, and then propagate down the ladle axis, ultimately "depositing" a quiescent layer on the bottom of the ladle.

Thus, the vectors shown in Figs. 1,2 and 3 must interpreted as showing the instantaneous velocity field calculated within the framework of a transient solution. Streamlines constructed from these vectors would not give a true representation of the long term movement of fluid within the ladle, so have not been presented in this paper.

The drainage curves shown in Figs. 8 and 9 are of the general form:

$$
T=a+b t+c \cdot e^{-d t}
$$

where, $\quad T$ : teeming temperature

$t:$ draining time ( $\propto$ tonnes drained)

$a, b, c, d$ : constants.

This correlation represents short-term exponential decay with a long term linear trend. Attempts to model this with a simple mixture of plug and perfectly mixed drainage fail, indicating the more complex threedimensional nature of withdrawal flow patterns.

The cooling rates used in the model have been assumed constant with time. The justification for this is that often this is the only information available from a plant statistical model. In the present case there is no reason why a time varying temperature loss could not be used. This is certainly an area of future possible refinement.

\section{Conclusions}

A mathematical model, based on the PHOENICS simulation package, has been developed to predict the evolution, with time, of liquid steel temperature and velocity fields during ladle standing and emptying.

Process parameters investigated were stand time, average cooling rate of the steel into the refractories, drainage rate and ladle geometry.

The main findings of the work may be summarized as follows:

(1) Thermal stratification will occur due to natural convection in a standing ladle. As time goes on the degree of stratification increases although the strength of the convection flows decrease.

(2) The simple empirical relationship, $\dot{\tau}=2.0 \dot{c}$, which has been derived from computer simulations, may be used to estimate the extent of stratification, where $\dot{\tau}$ is the rate of increase in temperature difference between the top and bottom of the steel, and $\dot{c}$ is the average cooling rate of the steel into the refractories. The simulations suggest that this relationship is independent of ladle size as it was shown to be valid for the ladles used at all BHP Steel production plants i.e. 125, 200, and 275 tonne ladles.

(3) As fluid flows out of the nozzle from a stratified ladle its temperature at the exit point reflects its origin in the ladle. Thus, stratification manifests itself at the teeming stage as a time-dependent tap temperature. These temperatures are, in turn, dependent on the drainage rate. High initial teeming rates promote fluid flow from the upper regions of the ladle, whilst at low drainage rates, the material that flows out comes primarily from the cooler zones adjacent to the nozzle. Consequently, rapid tundish filling will reduce the influence of ladle stratification.

(4) Plant trials have shown good agreement between simulated and actual teeming temperatures.

\section{Acknowledgements}

The authors wish to thank the support given by staff on the production plants at SPPD, RBPD and LPD. Particular thanks to Messrs. D. Varcoe and D. Trotter for conducting the plant trials and for helpful discus- 
sions. The PHOENICS numerical code is supplied to BHP under licence by CHAM Ltd., London.

\section{Nomenclature}

$\dot{c}$ : Bulk ladle cooling rate $\left({ }^{\circ} \mathrm{C} / \mathrm{min}\right)$

$c_{p}$ : Heat capacity $\left(\mathrm{J} / \mathrm{kg} \cdot{ }^{\circ} \mathrm{C}\right)$

$\widetilde{F}_{B}:$ Buoyancy force $\left(\mathrm{N} / \mathrm{m}^{3}\right)$

$\tilde{g}$ : Gravitational vector $\left(\mathrm{m} / \mathrm{s}^{2}\right)$

$h:$ Enthalpy $(\mathrm{J} / \mathrm{kg})$

$P$ : Pressure $(\mathrm{Pa})$

$T$ : Temperature $\left({ }^{\circ} \mathrm{C}\right)$

$T_{\text {ref }}:$ Reference temperature $\left({ }^{\circ} \mathrm{C}\right)$

$t$ : Time (s)

$\tilde{u}:$ Velocity $(\mathrm{m} / \mathrm{s})$

$\beta$ : Thermal expansion coefficient $\left(1 /{ }^{\circ} \mathrm{C}\right)$ $\mu_{l}: \quad$ Laminar viscosity $(\mathrm{Pa} \cdot \mathrm{s})$

$\mu_{t}:$ Turbulent viscosity $(\mathrm{Pa} \cdot \mathrm{s})$

$\rho:$ Density $\left(\mathrm{kg} / \mathrm{m}^{3}\right)$

$\sigma_{h}:$ Prandtl No. (一)

$\tau$ : Temperature stratification $\left({ }^{\circ} \mathrm{C}\right)$

$\dot{\tau}$ : Rate of stratification $\left({ }^{\circ} \mathrm{C} / \mathrm{min}\right)$

\section{REFERENCES}

1) R. Baker and W. R. Irving: Ironmaking Steelmaking, 8 (1981), 216

2) M. A. Omatani, L. J. Heaslip and A. Maclean: Ironmaking Steelmaking, 10 (1983), 29

3) J. W. Hlinka and T. W. Miller: Iron Steel Eng., 47 (1970), 123.

4) O. J. Ilegbusi and J. Szekeley: Trans. Iron Steel Inst. Jpn., 27 (1987), 563.

5) B. E. Launder and D. B. Spalding: Computer Methods in Applied Mech. and Eng., 3 (1974), 269. 